\title{
Values Congruence on CSR and Its Impact on Corporate Reputation
}

\author{
Songdi $\mathrm{Li}^{1}$, Louise Spry ${ }^{2}$ and Tony Woodall ${ }^{3}$
}

\begin{abstract}
Corporate Social Responsibility (CSR) is increasingly accepted by decision makers and implemented in businesses, because it is beneficial to an organization's profit and influence and also the perceptions and commitment of its stakeholders. Therefore, doing CSR is largely related to building a good reputation. Although the individual values of managers is more and more regarded as a driver CSR, and as the congruence between corporate values and employee values is known to impact CSR activities, the link between individual values and Corporate Reputation (CR) is an understudied topic. The purpose of this article is to propose how to investigate this issue in a higher education context. Exploring, a) to what extent university top managers and middle managers values concur in respect of CSR, and b) how this might impact on the CR which is perceived by other stakeholders are its chief focus. The proposed study is to be based on two case study universities, one in the UK and one in China. Both semi-structured interviews and surveys are proposed, representing a mixed methods approach to a complex problem. This study will benefit university top management in its CSR decision making.
\end{abstract}

Keywords: personal values, organisational values, values congruence, CSR, corporate reputation

\section{Introduction}

Corporate social responsibility (CSR) represents how an organisation is adheres to its ethical, economic, legal, philanthropic responsibilities (Carroll 1991) both for the whole of society and for its various stakeholders. Interchanging with the concept of 'sustainability' which promotes the interests of 'People, Planet, and Profit', CSR emphasises sustainable policy implementation in the organization (Van Marrewijk 2003). The concept of CSR suggests that an organisation should not only fulfil its duty on making profits for its investors and stockholders but also consider the benefit of other stakeholders, including employees and the local community.

Nowadays more and more top leaders and managers consider CSR as a strategy to differentiate themselves and gain competitive market advantage, because the successful conducting of CSR can bring about advanced value chain improvements which reduce costs and encourage innovation, competitive advantage, customer satisfaction (Porter and Kramer 2019) and eventually enhances the overall corporate reputation (CR; Fombrun 2005). The relationship between CSR and CR has been examined in multiple disciplines and from various theoretical angles, such as stakeholder theory (Sen and Bhattacharya 2001), reputational risk management (Gatzert 2015), and business ethics (Rossouw 2005). However, only a few scholars (e.g. Siltaoja 2006) have taken the concept of values as a lens to look into the CSR-CR relationship.

The literature on values suggests that personal values are powerful in guiding people's

| ${ }^{1} \mathrm{PhD}$ candidate and Lecturer of Nottingham Business School, Nottingham Trent University, United Kingdom

2Senior Lecturer in the Marketing Division at Nottingham Business School, Nottingham Trent University

${ }_{3}^{3}$ Principal Lecturer in Marketing Division at Nottingham Business School, Nottingham Trent University 
decisions and behaviours (Baumgartner 2014) and the Schwartz values theory proposes 10 basic but universally important value types (Schwartz 1992). Some people (e.g. Stead and Stead 2009; Frederick 1999) claim that inherent values (e.g. diversity, spiritual, fulfilment, community, etc.) motivate both top leader or managers to make ethical, moral and responsible decisions which enhance corporate performance and finally impact on the CR. It is also argued that age, gender, culture, firm size, managerial discretion, and contexts are mediators that can influence the final result either positively or negatively (Boohene, Sheridan and Kotey 2008; Ling, Zhao and Baron 2007).

Consequently, we argue that the concept of personal values could be used to explain how middle managers of a university understand institutional core values and why they may (or may not) favour the incorporation of CSR into their practice. For one thing, the CSR-related values of managers could enhance their individual performance which in turn might improve overall organizational performance. Further, the values congruence between managers and the organisation would to some extent also impact on CR. Hence, we propose a framework which demonstrates the formulation of values congruence between operational managers and the institution (organizational values) within a university and its impact on internal and external reputation. We intend to explore this in two national contexts, in both the UK and China.

The purpose of this paper is to describe a project designed to explore to what extent personal values and values congruence between middle managers and the institution would influence overall university reputation. To achieve this, both Schwartz values theory and stakeholder theory are applied to discover the relationship between multiple stakeholder groups, multi-dimensional reputation and cross-cultural perspectives. This paper consists of five sections. After the introduction, section two presents the interlinkage between CSR, $\mathrm{CR}$, personal values, values congruence and stakeholder theory. Next, we introduce a theoretical framework which adopts and modifies a research framework developed by Siltajao's (2006). The fourth section demonstrates a proposed research design which comprises five stages. Finally, we discuss the framework's relationship to the existing literature and suggest some concerns for future studies.

\section{Literature Review}

\subsection{CSR and its relationship with CR}

The concept of CSR has many definitions. For example, Carroll (1991) maintains CSR is a pyramid of responsibilities consisting of legal, ethical and philanthropic responsibilities that are organized to solve the ethical issues which emerge in business. Siltaoja (2006) describes CSR as an umbrella term which covers other similar existing concepts such as corporate citizenship, corporate social responsiveness, corporate accountability and corporate sustainability. Dahlsrud (2008) argues that CSR should focus on society and other stakeholders, although financial benefits should not be neglected. For corporate reputation Shenkar and Yuchtman-Yaar (1997) suggest this equates to corporate standing, esteem, organisational image, brand, corporate image, prestige, and goodwill. And some researchers find there is an antecedent role of CSR to CR - for instance, Fombrun, Gardberg and Barnett (2000) identify that executives intend to adopt CSR as a strategic tool to find opportunities and mitigate reputational risks. 
There are tools for measuring corporate reputation. For example, RepTrak has seven operational components: leadership, innovation, workplace, governance, product \& service, citizenship and performance, as well as four emotional elements: feeling, esteem, admiration and trust. Of the seven operational dimensions, three (workplace, governance, citizenship) are related to CSR (Fombrun, Ponzi and Newburry 2015). So it is clear that previous studies concerning either the definition and/or measurement of reputation all indicate the crucial role played by CSR.

\subsection{Personal values, values congruence and their relationships with CSR}

Rokeach (1973) defines personal values as enduring beliefs, and there are two types of personal values - terminal values (end-states of being, for example comfortable life and self-esteem) and instrumental values (modes of conduct likely to lead to those end states, such as open-mindedness and hard work). However, Schwartz (1992) suggests that personal values are conceptions of the desirable (motivations) that lead social participants to select, evaluate and explain their actions and evaluations. Later, Schwartz (1999) defined ten motivationally distinct value types over four dimensions - 1. openness: self-direction, stimulation, hedonism; 2. Conservation: traditional, security, conformity; 3. Selftranscendence: universalism, benevolence; and 4. Self-enhancement: achievement, power. These he suggests cover the core values recognised in cultures worldwide, and each primary value can be characterised by describing its central motivational goal.

Both Rokeach (1973) and Schwartz (2007) believe that ethics (doing good) and morality (justice) are particularly related to values that have an interpersonal focus and are considerably determined by societal culture. Such moral values are gradually incorporated into an organisation's business management strategy given that important stakeholder groups (see below section 3) are likely to have concerns about business ethics and their impact (Freeman, 2010). So managers' personal values are regarded as drivers of CSR, as managers values may motivate philanthropic activities (Hemingway and Maclagan, 2004). However, personal values might not be mutually experienced by different people, and/or in different time periods (i.e. businessman may not have considered social responsibility 100 years ago), and by different cultures (Allport, 1961). For example, China has a traditional culture based on Confucianism and which incorporates harmony, virtues, selfcultivation, reciprocity, and Taoist harmony. This has been the backbone of Chinese personal values for thousands of years playing an essential role in the contemporary Chinese values structure (Wang and Juslin, 2009). Hence, managers in China might have different perception and interpretation of CSR than do managers in other countries.

The values theories mentioned above indicate cognitive understandings of values as abstract principles (Gehman, Trevino and Garud, 2013) while in the business context and from the organizational culture perspectives, values are instilled into the organization through a top-down process and shared by employees. This suggests all stakeholders' views should be taken into account in relation to organization's values (Gehman, Trevino and Garud, 2013). Executives' personal values are regarded as drivers of CSR as they facilitate and motivate management to make ethical decisions, to embed CSR into the corporate values, and to communicate CSR through the organization practice (Suar and Khuntia, 2010). Personal values of organisational members, such as employees and middle-level managers, could help to reduce unethical practices and improve the well- 
being and citizenship behaviors in the organisation (Suar and Khuntia, 2010). In addition, Marcrus, MacDonald and Sulsky (2015) structure a value typology upon CSR elements and categorize values into economic, social and environmental values and each value plays an important role in determining propensity to engage in CSR actions.

The Schwartz value theory has become the most commonly applied of all values theories (Sagiv, Roccas, Cieciuch, and Schwartz, 2017) and has been tested (e.g. Lee, Sneddon, Daly, Schwartz, Soutar, and Louviere, 2017), refined (e.g. Schwartz, Cieciuch, Vecchione, Davidov, Fischer, Beierlein, Ramos, Verkasalo, Lönnqvist, Demirutku, and DirilenGumus, 2012), extended (Schwartz, S.H., Melech, G., Lehmann, A., Burgess, S., Harris, M. and Owens, V., 2001) and summarized (Schwartz 2012). Further, this has been applied widely in empirical/practical research on CSR (Wang and Juslin, 2011), on organisational values (Finegan 2000)), and on organisational behavior (Krystallis, Vassallo, and Chryssohoidis 2012). Although Schwartz's value theory has mostly been applied in quantitative researche, both Siltaoja (2006) and Torres Fernández de Castro (2015) have conducted interviews, and from transcripts have coded Schwartz's 10 basic human values. These represent the inspiration for the present research design.

\subsection{Stakeholder theory in CR, CSR, personal values and values congruence}

In the reputation literature, stakeholder theory is usually used to define reputation in different contexts and interpretations (Esen 2013 and Bromley 2000). Freeman (2010) and Newburry (2010) state that businesses have obligations to a broader group of stakeholders than just shareholders because other stakeholders' perceptions of the firm and the interaction and communication between stakeholder groups is crucial to the reputation creation process. This is known as dynamic reputation enactment. Further, Hemphill (2006) maintains that reputation is a combination of reality and perception, and this is represented by the performance perceived by key stakeholders. Reputation, for the same firm, can vary considerably across different stakeholder groups. It can be well regarded by one external stakeholder group but reviled by another (Ravasi 2002). This is because different stakeholders have different contexts and use varying ways to interpret received information.

So it is important that the needs, perceptions and attitudes of all groups are understood. According to Hillenbrand and Money (2007), CSR can be separated into eight clusters of responsibility in accordance with stakeholder theory. Consequently, CSR dimensions express the same meaning as reputation dimensions. With respect to business, the contradictory demands of social contribution and commercial benefit also reflects on the balance of a leader's self-interest values and also other-caring values (Jones, Felp and Bigley 2007). Top manager's values might also be described as entrepreneur values, executive values or CEO values. These have attracted a lot of attention and researchers have suggested that, on the one hand, some top manager values - for example community, diversity, power, and quality- are linked to morality and care for others which then encourage CSR strategy, policy and practices (Stead and Stead 2009; Frederick 1999). On the other hand, top manager who intend to care about others could arise values congruence with organisational members in terms of taking social responsibilities and doing CSR practices. Values of other stakeholder segments, students for example, may also determine their perceptions and attitudes on university CSR 
implementation (Wang and Juslin 2012), given that - as customers - their values may direct their purchase behaviours (Piercy and Lane 2009). Thus, values congruence in the organisational area covers multiple pairs of stakeholder groups, such as leader-supervisor; employee-employee; employee-leader; employee-team; employee-organisation; customerorganisation, and etc. (Maierhofer, Kabanoff and Griffin 2002).

In summary, this literature review suggests that both CR and the values concept are highly related to both CSR theory and stakeholder theory. Currently, the concept of values are increasingly used to explain phenomena happen in business management, and people's values, attitudes, and emotions are increasingly studied within the organisational context (Hemingway and Maclagan 2004), Siltaoja (2006) has implicitly suggested that employees' personal values and congruence with the firm's CSR-related values will influence CR. hence, this paper extended Siltaoja's (2006) framework to discover to what extent the personal values of an operation manager will influence the CR and how this influence would be different in regard to the higher education context.

\section{Conceptual Framework}

The conceptual framework (see Figure 1) shows how values theory, CR, stakeholder theory and CSR theory are related. The relevant university stakeholder groups identified for data collection are divided into top management (for example, Vice-chancellor, Pro Vice-chancellor and board of governors), operational managers (for instance, HR manager, marketing manager etc.) and other stakeholders (such as students, staff etc.). Regarding CSR in the university, operational managers will influence CR as a function of the values fit (congruence) between their personal values and the organisational values expressed by top management. It is suggested that CSR implementation perspectives held by operation managers will be influenced by this. Further, other stakeholders - such as students, employees, local businesses and alumni will build their perceptions of university CR partially as a function of the effect that this values congruence has. Collectively, the factors that influence both values congruence and CR - and how these might differ between a UK and a Chinese institution - are questions that will be explored in the proposed study.

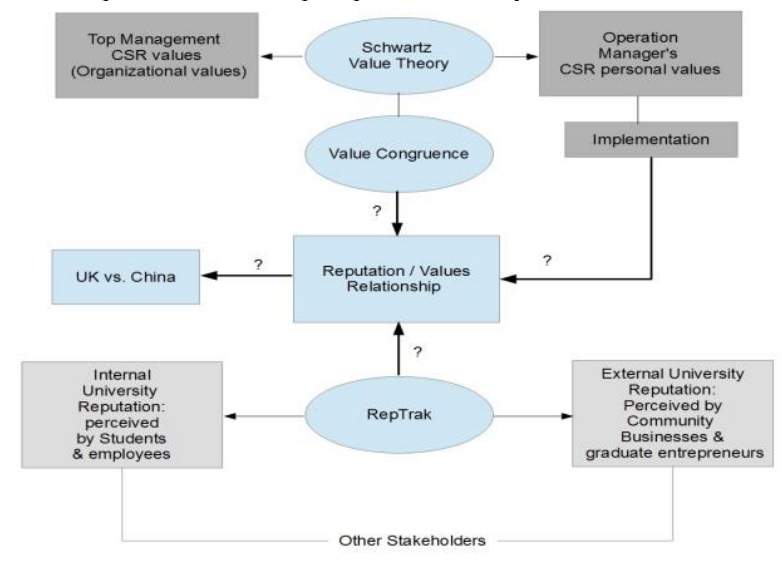

Figure 1. Conceptual framework 


\section{Methodology}

This research applies a research design based on the well-known 'research onion' (Saunders, Lewis, and Thornhill 2007) as follows:

\subsection{Research philosophy}

Regarding the concerns of ontology and epistemology, the project is a process of investigating people's perceptions of reputation and CSR and trying to interpret and explain them. The authors consequently adopt a broadly subjective ontology and an interpretivist epistemology. However, this will be a mixed methods project that adopts a pragmatist position (Johnson and Onwuegbuzie 2004) that allows for the collection of both qualitative and quantitative data and will consequently incorporate both.

\subsection{Research approach}

An inductive approach will be combined with a deductive approach. Although this research will be conducted step by step under the guidance of a conceptual framework, the intention is not to test existing theories but to use them to generate new theory. This will be based on an exploration of the relationships/differences between stakeholder groups and also between institutions in different parts of the world. Mixed methods are primarily employed so that quantitative measures of both personal values (for operational managers) and corporate reputation (as viewed by 'other stakeholders') can be incorporated into the study. However, comparisons of both stakeholder groups and institutions will be undertaken interpretively.

\subsection{Research design}

The whole study is based on two case studies, in both UK and Chinese universities. Research will use both semi-structured interviews and surveys. Case study work can help make comparison between cases that cross cultures and can help acquire an insight derived from multiple stakeholders (Yin 2003). Data will be collected from a UK university (Nottingham Trent University, NTU) and a Chinese university (still to be confirmed). The Chinese university though will also be a mid-range institution similar to NTU. NVIVO and SPSS will be used to analyse qualitative and quantitative data respectively with personal sense-making used to perform congruence analyses. The research is divided into four stages as below.

\subsection{Research stages}

\subsubsection{Stage 1}

The values of the those responsible for university CSR strategy (VC, Board of Governors, Pro-VCs in the case of NTU) will be evaluated indirectly. As relevant university officers will be difficult to reach, and not likely to submit to a formal values questionnaire, then guiding values will be assessed in two ways. Firstly, current policy documents/publications will be made subject of an interpretive CSR-based values review, using the Schwartz value survey (Schwartz 1994) as a template for analysis. Secondly, the Pro-Vice Chancellor responsible for implementing CSR policy (and equivalent for China) will be interviewed to both confirm and improve this analysis. 


\subsubsection{Stage 2}

15 to 20 operational managers from each institution will be asked for a semistructured interview to determine managers' views on CSR strategies and other factors that influence their CSR implementation, for example communication with and from top management and resource allocation/availabity. They will also be asked to complete the Schwartz value survey (Schwartz 1994).

\subsubsection{Stage 3}

A survey adapted from the RepTrak Scorecard (Ponzi, Fombrun and Gardberg 2011) will be sent to internal (students and staff) and external (graduates, community members) stakeholders to surface their perceptions of university reputation. RepTrak is selected as it is found to be both reliable and cross-culturally validated. It is also strongly linked to the CSR concept. A total of 120 respondents will be sought for each institution, 30 from each of four demand-side groups (internal: students and academic staff; and external: community and business groups).

\subsubsection{Stage 4}

Sense-making will then be used to evaluate and explain the potential relationship between values congruence of different management level stakeholders, and other stakeholders' perceptions of CSR-focused reputation. Middle managers' perceptions on implementation issues (e.g. between-level communication and resource allocation) will also be assessed.

\subsubsection{Stage 5}

Chinese and UK institutions will be compared in terms of values congruence (between top management and operational managers) and also operational managers' perceptions on policies, strategies and resource allocations that may either help or hinder them.

\section{Discussion and Conclusion}

In the literature, personal values - whether relating to top managers or to staff influence perceptions, attitudes and action in respect of CSR. All this could impact on personal performance, which in turn and to some extent will influence overall CR. When individual value priorities match with organizational aspirations about CSR, this congruence will motivate CSR activities, job satisfaction, corporate citizenship behaviours. It can lead to the advanced performance at the individual, the team and the entire organizational levels. Therefore, we argue that personal values and values congruence regarding CSR could influence overall CR. And we can explore this assumption by exploring how a person's values and its congruence with organizational values would associate to each of the RepTrak dimensions: performance, innovation, leadership, workplace, citizenship, governance and attitude towards the organization. However, there are some points that need to be noted and addressed.

Personal values and the person-organisation fit are indirectly linked to CR, and are likely to moderate corporate performance. However, individual values and values congruence 
could impact performance in different ways. Contextual performance, task performance (Goodman and Svyantek 1999), social performance, and financial performance (Waddock and Graves 1997) are all relevant to the overall organisation performance. And specific values might be found to be significantly related to one type of performance but have no relationship with another (Adkins and Russell 1997; Glew 2009; Parks and Guay 2012). Furthermore, the different levels at which values congruence can occur (e.g. employ-employee, employee-organization, employee-leader) implies that recognising the most relevant groups of stakeholder that are significant for studying CSR values is important.

Siltaoja (2006) suggests that personal values are key to understanding the link between CSR and CR. However, we do not know which specific values are related to CSR in the HE context. Further, how these individual CSR values and the congruence between different levels of management impact each CR/RepTrak dimension not known. For example, we might find out the person-organisation fit is positively associated with performance dimension, but has no relationship with the service and product dimensions. Also, there might be values incongruence and this may impact negatively on CR.

Although Schwartz values theory is validated across cultures and has become increasingly popular in investigating CSR issues in many countries, Chinese perceptions on CSR will likely be impacted by Confusion values which are distinct from those in the West (Shafer, Fukukawa, and Lee 2007). Therefore, these cultural differences should be taken into account in any study using the Schwartz values theory.

Overall, we seek to contribute to knowledge by integrating values theory into the business area, and also by taking a mixed methods approach to research. From a practical view our proposed framework could help top managers to realize the relevance of personal characteristics in achieving CSR, and by working to achieve shared CSR values could benefit CR in many ways.

\section{References}

Adkins, C. L., \& Russell, C. J. (1997). Supervisor-subordinate work value congruence and subordinate performance: A pilot study. Journal of Business and Psychology, 12(2), 205-218.

Allport, G. W. (1961). Pattern and growth in personality.

Baumgartner, R. J. (2014). Managing corporate sustainability and CSR: A conceptual framework combining values, strategies and instruments contributing to sustainable development. Corporate Social Responsibility and Environmental Management, 21(5), 258-271.

Boohene, R., Sheridan, A., \& Kotey, B. (2008). Gender, personal values, strategies and small business performance: A Ghanaian case study. Equal Opportunities International, 27(3), 237-257.

Bromley, D. B. (2000). Psychological aspects of corporate identity, image and reputation. Corporate reputation review, 3(3), 240-252.

Carroll, A. B. (1991). The pyramid of corporate social responsibility: Toward the moral management of organizational stakeholders. Business horizons, 34(4), 39-48.

Carroll, A. B. (1991). The pyramid of corporate social responsibility: Toward the moral management of organizational stakeholders. Business borizons, 34(4), 39-48.

Dahlsrud, A. (2008). How corporate social responsibility is defined: an analysis of 37 definitions. Corporate social responsibility and environmental management, 15(1), 1-13. 
Esen, E. (2013). The influence of corporate social responsibility (CSR) activities on building corporate reputation. In International business, sustainability and corporate social responsibility (pp. 133-150). Emerald Group Publishing Limited.

Finegan, J. E. (2000). The impact of person and organizational values on organizational commitment. Journal of occupational and Organizational Psychology, 73(2), 149-169.

Fombrun, C. J. (2005). A world of reputation research, analysis and thinking-building corporate reputation through CSR initiatives: evolving standards. Corporate reputation review, 8(1), 7-12.

Fombrun, C. J., Gardberg, N. A., \& Barnett, M. L. (2000). Opportunity platforms and safety nets: Corporate citizenship and reputational risk. Business and society review, 105(1), 85-106.

Fombrun, C. J., Ponzi, L. J., \& Newburry, W. (2015). Stakeholder tracking and analysis: The RepTrak ${ }^{\circledR}$ system for measuring corporate reputation. Corporate Reputation Review, 18(1), 3-24.

Frederick, W. C. (1999). Colloquium: Reflections on Frederick's values, nature, and culture in the American corporation. Business and Society, 38(2), 206-211.

Freeman, R. E. (2010). Strategic management: A stakeholder approach. Cambridge university press.

Freeman, R. E. (2010). Strategic management: A stakeholder approach. Cambridge university press.

Gatzert, N. (2015). The impact of corporate reputation and reputation damaging events on financial performance: Empirical evidence from the literature. European Management Journal, 33(6), 485-499.

Gehman, J., Treviño, L. K., \& Garud, R. (2013). Values work: A process study of the emergence and performance of organizational values practices. Academy of Management Journal, 56(1), 84-112.

Glew, D. J. (2009). Personal values and performance in teams: An individual and team-level analysis. Small Group Research, 40(6), 670-693.

Goodman, S. A., \& Svyantek, D. J. (1999). Person-organization fit and contextual performance: Do shared values matter. Journal of vocational behavior, 55(2), 254-275.

Hemingway, C. A., \& Maclagan, P. W. (2004). Managers' personal values as drivers of corporate social responsibility. Journal of Business Ethics, 50(1), 33-44.

Hemingway, C. A., \& Maclagan, P. W. (2004). Managers' personal values as drivers of corporate social responsibility. Journal of Business Ethics, 50(1), 33-44.

Hemphill, T. A. (2006). Corporate internal investigations: balancing firm social reputation with board fiduciary responsibility. Corporate Governance: The international journal of business in society, 6(5), 635-642.

Hillenbrand, C., \& Money, K. (2007). Corporate responsibility and corporate reputation: two separate concepts or two sides of the same coin?. Corporate Reputation Review, 10(4), 261-277.

Johnson, R. B., \& Onwuegbuzie, A. J. (2004). Mixed methods research: A research paradigm whose time has come. Educational researcher, 33(7), 14-26.

Jones, T. M., Felps, W., \& Bigley, G. A. (2007). Ethical theory and stakeholder-related decisions: The role of stakeholder culture. Academy of Management Review, 32(1), 137-155.

Krystallis, A., Vassallo, M., \& Chryssohoidis, G. (2012). The usefulness of Schwartz's 'Values Theory' in understanding consumer behaviour towards differentiated products. Journal of Marketing Management, 28(11-12), 1438-1463.

Lee, J. A., Sneddon, J. N., Daly, T. M., Schwartz, S. H., Soutar, G. N., \& Louviere, J. J. (2019). Testing and extending Schwartz Refined Value Theory using a best-worst scaling approach. Assessment, 26(2), 166-180.

Ling, Y., Zhao, H., \& Baron, R. A. (2007). Influence of founder-CEOs' personal values on firm performance: Moderating effects of firm age and size. Journal of Management, 33(5), 673-696.

Maierhofer, N. I., Kabanoff, B., \& Griffin, M. A. (2002). The influence of values in organizations: Linking values and outcomes at multiple levels of analysis. International review of industrial and organizational psychology, 17, 217-264.

Marcus, J., MacDonald, H. A., \& Sulsky, L. M. (2015). Do personal values influence the propensity for sustainability actions? A policy-capturing study. Journal of Business Ethics, 127(2), 459-478.

Newburry, W. (2010). Reputation and supportive behavior: Moderating impacts of foreignness, industry and local exposure. Corporate Reputation Review, 12(4), 388-405.

Parks, L., \& Guay, R. P. (2012). Can personal values predict performance? Evidence in an academic setting. Applied psychology, 61(1), 149-173.

Piercy, N. F., \& Lane, N. (2009). Corporate social responsibility: impacts on strategic marketing and customer value. The Marketing Review, 9(4), 335-360. 
Porter, M. E., \& Kramer, M. R. (2019). Creating shared value. In Managing sustainable business (pp. 323-346). Springer, Dordrecht.

Ravasi, D. (2002). Analysing Reputation in a Cross-national Setting: Evidence from Italy. Corporate Reputation Review, 4(4).

Rokeach, M. (1973). The nature of human values. Free press.

Rossouw, G. J. (2005). Business ethics and corporate governance in Africa. Business \& Society, 44(1), 94-106.

Sagiv, L., \& Schwartz, S. H. (2007). Cultural values in organisations: insights for Europe. European Journal of International Management, 1(3), 176-190.

Sagiv, L., Roccas, S., Cieciuch, J., \& Schwartz, S. H. (2017). Personal values in human life. Nature Human Behaviour, 1(9), 630.

Saunders, M., Lewis, P., \& Thornhill, A. (2007). Research methods. Business Students 4th edition Pearson Education Limited, England.

Schwartz, S. H. (1992). Universals in the content and structure of values: Theoretical advances and empirical tests in 20 countries. In Advances in experimental social psychology (Vol. 25, pp. 1-65). Academic Press.

Schwartz, S. H. (1992). Universals in the content and structure of values: Theoretical advances and empirical tests in 20 countries. In Advances in experimental social psychology (Vol. 25, pp. 1-65). Academic Press.

Schwartz, S. H. (1994). Are there universal aspects in the structure and contents of human values?. Journal of social issues, 50(4), 19-45.

Schwartz, S. H. (1999). A theory of cultural values and some implications for work. Applied psychology, 48(1), 23-47.

Schwartz, S. H., Cieciuch, J., Vecchione, M., Davidov, E., Fischer, R., Beierlein, C., ... \& Dirilen-Gumus, O. (2012). Refining the theory of basic individual values. Journal of personality and social psychology, 103(4), 663.

Sen, S., \& Bhattacharya, C. B. (2001). Does doing good always lead to doing better? Consumer reactions to corporate social responsibility. Journal of marketing Research, 38(2), 225-243.

Shafer, W. E., Fukukawa, K., \& Lee, G. M. (2007). Values and the perceived importance of ethics and social responsibility: The US versus China. Journal of Business Etbics, 70(3), 265-284.

Shenkar, O., \& Yuchtman-Yaar, E. (1997). Reputation, image, prestige, and goodwill: An interdisciplinary approach to organizational standing. Human Relations, 50(11), 1361-1381.

Siltaoja, M. E. (2006). Value priorities as combining core factors between CSR and reputation-a qualitative study. Journal of Business Ethics, 68(1), 91-111.

Stead, J. G., \& Stead, W. E. (2009). Management for a small planet (3" ed.). Armonk, NY: ME Sharpe.

Suar, D., \& Khuntia, R. (2010). Influence of personal values and value congruence on unethical practices and work behavior. Journal of Business Ethics, 97(3), 443-460.

Torres Fernández de Castro, J. G. (2015). Qualitative Content Analysis as an Exploratory Method for Measuring Values and Political Attitudes.(Master's thesis). Retrieved from https://helda.helsinki.fi/bitstream/handle/10138/155253/TORRES_SocialPsychology.pdf?seque nce $=2$

Van Marrewijk, M. (2003). Concepts and definitions of CSR and corporate sustainability: Between agency and communion. Journal of business ethics, 44(2-3), 95-105.

Waddock, S. A., \& Graves, S. B. (1997). The corporate social performance-financial performance link. Strategic management journal, 18(4), 303-319.

Wang, L., \& Juslin, H. (2009). The impact of Chinese culture on corporate social responsibility: The harmony approach. Journal of Business Ethics, 88(3), 433-451.

Wang, L., \& Juslin, H. (2011). The effects of value on the perception of corporate social responsibility implementation: A study of Chinese youth. Corporate Social Responsibility and Environmental Management, 18(4), 246-262.

Wang, L., \& Juslin, H. (2012). Values and corporate social responsibility perceptions of Chinese university students. Journal of Academic Ethics, 10(1), 57-82.

Yin, R. K. (2003). Case study research: Design and methods (Vol. 5).

Zhang, K., Wang, S., Malhotra, J., Hassler, J. R., Back, S. H., Wang, G., ... \& Chen, Y. E. (2011). The unfolded protein response transducer IRE1 $\alpha$ prevents ER stress- induced hepatic steatosis. The EMBO journal, 30(7), 1357-1375. 